\title{
Sero-epidemiological survey of Crimean-Congo hemorrhagic fever virus in Tunisia
}

Fares Wasfi ${ }^{1, \mathrm{a}}$, Stuart Dowall ${ }^{2, \mathrm{a}}$, Tayssir Ghabbari ${ }^{3}$, Andrew Bosworth ${ }^{2}$, Mohamed Chakroun ${ }^{4}$, Anitha Varghese ${ }^{2}$, Hanene Tiouiri ${ }^{5}$, Mounir Ben Jemaa ${ }^{6}$, Abir Znazen ${ }^{6}$, Roger Hewson ${ }^{2,7}$, Elyes Zhioua ${ }^{1, *}$, and Amel Letaief ${ }^{3}$

1 Institut Pasteur de Tunis, Laboratory of Vector Ecology, 13 Place Pasteur, 1002 Tunis, Tunisia

2 Public Health England, Porton Down, Salisbury, Wiltshire SP4 0JG, UK

3 Infectious Diseases Department, Farhat Hached University Hospital, 4004 Sousse, Tunisia

4 Infectious Diseases Department, Fatouma Bourguiba University Hospital, 5000 Monastir, Tunisia

5 Infectious Diseases Department, 3000 Sfax, Tunisia

6 Laboratory of Microbiology, 3000 Sfax, Tunisia

7 National Institute of Health Research, Health Protection Research Unit in Emerging and Zoonotic Infections, L3 5RF Liverpool, UK

Received 26 January 2016, Accepted 23 February 2016, Published online 8 March 2016

\begin{abstract}
Crimean-Congo hemorrhagic fever (CCHF) is a tick-borne disease associated with a high case fatality rate and transmitted mainly by Hyalomma marginatum. The geographical distribution of $H$. marginatum covers most of the Western Mediterranean basin. We aimed to investigate whether CCHF virus (CCHFv) is circulating in Tunisia. Samples from unexplained acute febrile patients $(n=181)$ and a high risk group of humans, mainly slaughter workers $(n=38)$, were collected in the summer of 2014 and analyzed for exposure to CCHFv using serological tests and real-time RT-PCR. Ticks were collected from Northern and Southern Tunisia during May-June 2014 and examined for the presence of CCHFv by real-time RT-PCR. Of the 181 febrile patients, 5 showed only high titers of IgM suggesting a recent exposure to CCHFv. Among 38 slaughter workers, 2 had IgG anti-CCHFv responses yielding a seroprevalence of 5.2\%. No CCHFv was detected in ticks and sera. Our results provide evidence of human exposure to CCHFv in Tunisia.
\end{abstract}

Key words: CCHF, CCHF virus, Seroprevalence, Ticks, Tunisia.

\begin{abstract}
Résumé - Enquête séro-épidémiologique sur le virus de la fièvre hémorragique de Crimée-Congo en Tunisie. La fièvre hémorragique de Crimée-Congo (FHCC) est une maladie transmise par les tiques, associée à un taux de létalité élevé, et transmise principalement par Hyalomma marginatum. La répartition géographique de H. marginatum couvre la majeure partie du bassin méditerranéen occidental. Nous avons cherché à déterminer si le virus de la FHCC (FHCCv) circule en Tunisie. Les échantillons provenant de patients ayant des fièvres aiguës inexpliquées $(n=181)$ et d'un groupe de personnes à haut risque, principalement des bouchers d'abattoirs $(n=38)$, ont été recueillis pendant l'été 2014 et analysés pour exposition à la FHCC en utilisant un test sérologique et par PCR en temps réel (RT-PCR). Les tiques ont été recueillies du Nord et du Sud de la Tunisie en mai-juin 2014 et examinées pour la présence de FHCCv par RT-PCR. Sur les 181 patients fébriles, 5 ont présenté seulement des titres élevés d'IgM suggérant une exposition récente au FHCCv. Parmi les 38 travailleurs d'abattoirs, 2 avaient des réponses IgG anti FHCCv, indiquant une séroprévalence de $5.2 \%$. Aucun FHCCv n'a été détecté dans les tiques et les sérums. Nos résultats fournissent des preuves de l'exposition humaine au FHCCv en Tunisie.
\end{abstract}

\section{Introduction}

Crimean-Congo hemorrhagic fever virus (CCHFv) (family Bunyaviridae, genus Nairovirus) is the etiologic agent of Crimean-Congo hemorrhagic fever (CCHF), a severe acute febrile illness characterized by fever and hemorrhage with case fatality rates of $9-50 \%[6,28]$. CCHF is the most widespread tick-borne disease in the world [12]. It has been reported in more than 30 countries including in Africa [22, 29], Asia [14, 21], the Middle East [25],

\footnotetext{
${ }^{a}$ The first two authors contributed equally to this work and should be considered as first authors

*Corresponding author: elyes.zhioua@gmail.com
} 
and has seen a significant increase during the last decade in Eastern Europe [10, 31].

$\mathrm{CCHFv}$ is maintained in nature through a transmission cycle involving ticks and vertebrate hosts and is transmitted mainly through the bite of ixodid ticks [7, 9, 12, 26, 30]. $\mathrm{CCHFv}$ has been isolated from several ixodid tick species including Hyalomma marginatum [10, 26, 30], Hyalomma dromedarii [30], Hyalomma anatolicum [21, 30], Hyalomma detritum [30], Hyalomma asiaticum [30], Rhipicephalus sanguineus [10], Rhipicephalus bursa [26], Rhipicephalus eversti [22], Ixodes ricinus [10, 26], and Hyalomma lusitanicum [7]. In the western Palearctic, $H$. marginatum is considered as the main vector of CCHFv [8]. H. marginatum is a two-host tick with larvae and nymphs feeding mainly on small mammals and birds while adults feed on large mammals including livestock [12]. Migratory birds play a significant role in spreading CCHFv between Africa and Europe [15, 17, 24]. While $\mathrm{CCHFv}$ is mainly transmitted through tick bites, humans may also become infected through direct contact with the blood or tissues of infected humans or livestock [14, 19, 21, 22]. Thus, farmers and butchers are at high risk for $\mathrm{CCHFv}$ infection [21, 22].

$\mathrm{CCHFv}$ has previously been isolated from $H$. marginatum collected from migratory birds from Morocco [24]. The geographical distribution of $H$. marginatum also covers Tunisia [20]. Thus, Tunisia could be at risk for CCHFv. In this study, we aimed to perform a sero-epidemiological survey to test for circulation of CCHFv in Tunisia and to assess samples of Hyalomma spp. ticks for the presence of viral RNA.

\section{Materials and methods}

\section{Study sites}

Tunisia covers a wide climatic range, from the Mediterranean climate with its rainy winter in the north to the Saharan climate in the south. The northern part of the country is separated from the south by the Tunisian Ridge. The latter is a range of hills which runs from north-east to south-west for some $220 \mathrm{~km}$, marking the climatic boundary between the Mediterranean north and the dry steppe of Central Tunisia. Between the northern slopes of the Tunisian Ridge and the chains of hills bounding it to the south are extensive plateaus, called the High Tell. The Sahara is separated from the central steppe land by a series of salted areas called chotts (Fig. 1).

\section{Study population}

Samples were collected from patients attending hospitals who had reported fever $(n=181)$. Samples were also actively taken from abattoir workers $(n=38)$ in order to survey evidence of previous exposure among a group designated as high risk. Most of the participants originated from the governorates of Sousse, Sfax, and Mahdia (Fig. 1), and samples were collected during summer 2014. All participants were asked for a history of tick bites and travel history. Samples were collected by vacutainer and the plasma was separated, frozen at $-20{ }^{\circ} \mathrm{C}$, and transported to Porton Down, UK for analysis.

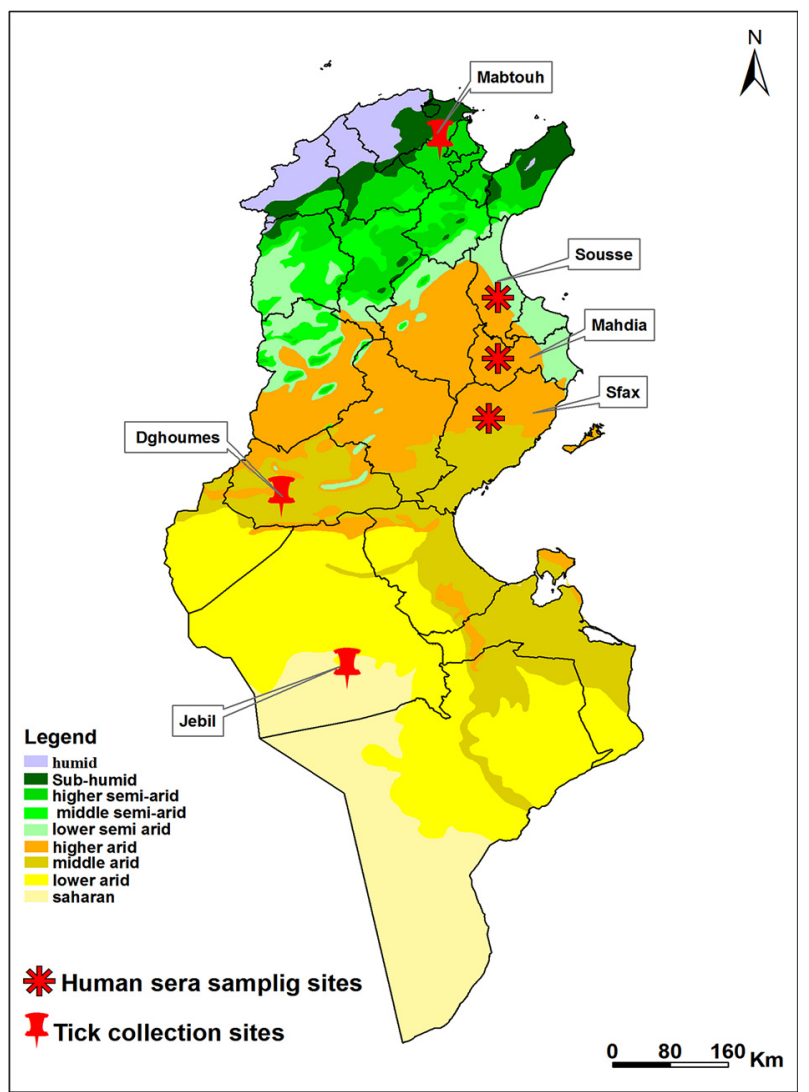

Figure 1. Bioclimatic map of Tunisia showing sites of sera and tick collection

All the abattoir worker donors were healthy without fever symptoms and the median age was 39 years (range 20-59).

Ticks were collected over the period May-June 2014 from cattle in barns in the region of Mabtouh, a known focus of theileriosis located in North Tunisia (Fig. 1) [11]. In addition, ticks were collected from the National Parks of Dghoumes and Sidi Touil located in Southern Tunisia from the resting sites of oryx (Fig. 1).

\section{Serological analysis}

The collected samples from patients were tested for the presence of IgG and IgM anti-CCHFv by ELISA test according to the instructions of the manufacturer (Vector-Best, Russia). The study was conducted under ethical approval from the Ethics Committee HHS-IRB 00008931, University Hospital Farhat Hached, protocol reference date 08-04-2013.

\section{Molecular analysis}

Ticks and human sera were examined for the presence of CCHFv by real-time RT-PCR [1]. Collected ticks were pooled according to the trapping location with a maximum of 10 specimens per pool for the non-engorged ticks and 2 per pool for engorged ticks, resulting in a total of 46 pools. The pools of ticks were transferred to Precellys tubes containing silica beads 
Table 1. List of positive samples, cohorts they belong to, and the associated results.

\begin{tabular}{|c|c|c|c|c|c|}
\hline Sample ID & Type & $\operatorname{IgG}$ & $\operatorname{IgM}$ & Confirmation & Outcome \\
\hline TUN/013 & Slaughter worker Sera & $1: 100$ & Negative & IgG positive & CCHF IgG positive \\
\hline TUN/024 & Slaughter worker Sera & $1: 100$ & Negative & IgG positive & CCHF IgG positive \\
\hline TUN/063 & Febrile patient & Negative & $1: 100$ & IgM positive & CCHF IgM positive \\
\hline TUN/080 & Febrile patient & Negative & $1: 100$ & IgM positive & CCHF IgM positive \\
\hline TUN/124 & Febrile patient & Negative & $1: 100$ & IgM positive & CCHF IgM positive \\
\hline TUN/187 & Febrile patient & Negative & $1: 100$ & IgM positive & CCHF IgM positive \\
\hline TUN/190 & Febrile patient & Negative & $1: 100$ & IgM positive & CCHF IgM positive \\
\hline
\end{tabular}

and $0.5 \mathrm{~mL}$ of Minimum Essential Medium (MEM), homogenized three times at $5600 \mathrm{rpm}$ for $30 \mathrm{~s}$, and finally centrifuged at $6000 \mathrm{rpm} / 15 \mathrm{~min}$. The total RNA was extracted according to the Qiagen Viral RNA Mini Kit from human sera and tick supernatant. The presence of CCHFv RNA was determined by qualitative real-time reverse transcription PCR performed on the $\mathrm{S}$ segment using the combination of the primer pairs CCHFV.S122F (5'CCT TTT TGA ACT CTT CAA ACC $\left.3^{\prime}\right) /$ CCHFV.S1R (5'TCT CAA AGA AAC ACG TGC C $\left.3^{\prime}\right)$ and the CCHFv probe (5'FAM $3^{\prime}$ ACT CAA GGK AAC ACT GTG GGC GTA AG-BHQ1), as published previously [1]. The real-time RT-PCR was performed using the SuperScript III Platinum One-Step qualitative RT-PCR system (Invitrogen Life Technologies) according to the manufacturer's instructions. One high and one low CCHFv viral RNA were used as a positive control. A volume of $5 \mu \mathrm{L}$ of total RNA extracted was used for CCHFv genome detection.

\section{Results}

Samples collected from patients with acute fever were initially tested according to local protocols for serological reactivity to Brucella, Rickettsia, and West Nile virus (WNV). All samples in this study were shown to be negative during the testing phase and were then analyzed for CCHF by serological testing. Of a total of 181 sera from febrile patients, $5(2.7 \%)$ showed high titers of IgM anti-CCHFv activity with an absence of IgG (Table 1). None of the patients had traveled to known overseas endemic areas for CCHF nor reported a history of tick bites. The presence of IgG anti-CCHFv was observed in 2 out of 38 slaughter workers, leading to a seroprevalence of $5.2 \%$. No positive cases of CCHFv were detected by RT-PCR analysis.

A total of 310 ticks were collected over the period May-June 2014 in three different collection sites. Ticks collected from Mabtouh, a known endemic focus for theileriosis, were identified as Hyalomma scupense. All ticks collected from Daghounes and Sidi Toui were identified as $H$. dromedarii. No $H$. marginatum were collected. RT-PCR analysis failed to detect the presence of $\mathrm{CCHFv}$ RNA, indicating that ticks were not carrying $\mathrm{CCHFv}$.

\section{Discussion}

Five febrile patients tested positive for IgM, which suggests recent infection. Since most patients were discharged, no second blood samples were taken to be tested for the presence of IgG anti-CCHFv. Hemorrhagic manifestations were not observed in any febrile patients. Therefore, as reported in Greece [27] and Turkey [2], it appears that the majority of infections were subclinical.

In our study, a seroprevalence of $5.2 \%$ was observed among slaughter workers, suggesting predominance of subclinical forms. Similar seroprevalence concerning high risk populations was reported from other endemic countries: Mauritania (7\%) [22]; Greece (4.2\%) [27]; Kosovo (4\%) [9]; Bulgaria (2.8\%) [5]; Turkey (2.3\%) [2]; and Iran (12\%) [4]. Our results provide more evidence that slaughtering and agricultural activities are significant risk factors for seropositivity [27].

In our study, no CCHFv was detected in the analyzed ticks. Hyalomma scupense is the main vector of Theileria annulata, etiologic agent of theileriosis in North Africa [11]. H. scupense completes its life cycle within the protection of walls and crevices of barns without any other host beside livestock, and subsequently, this tick species has not been implicated in the transmission of CCHFv [23]. Hyalomma dromedarii were collected only from the vegetation and from resting sites of oryx and not from livestock (cattle, sheep, or dromedary), known to be the main amplifying hosts for CCHFv [12]. Hyalomma marginatum, a main vector of CCHFv, is located mainly in the Northwestern part of Tunisia [20], an area that was not investigated during the study period. Thus, further studies concerning $H$. marginatum are needed.

Our results suggest circulation of CCHFv in Tunisia. The seroprevalence observed among the high risk population was not unexpected mainly because of the circulation of CCHFv among populations of $H$. marginatum in North Africa. To date, no clinical cases of CCHF (fever followed by hemorrhagic manifestations) have been observed in North Africa. It is of major epidemiological importance to point out that the detection of CCHFv in $H$. marginatum collected from birds in Morocco and in $H$. aegyptium collected from tortoises in Algeria provides strong evidence that the virus is transmitted in North Africa mainly by ticks belonging to the genus Hyalomma $[13,24]$. The detection of the non-pathogenic CCHFv strain AP92 (Europe 2) in H. aegyptium collected from tortoises in Algeria [13] could explain in part the absence of clinical cases in the Western Mediterranean basin [27]. This hypothesis is corroborated by the fact that the low-pathogenic viruses found in Greece are phylogenetically close to known sequences from African strains [17]. The geographical distribution of clinical cases of CCHF is limited to the Western Balkans. However, the geographical distribution of H. marginatum covers significantly larger areas including Spain, Southern Italy, and North Africa. The absence of human 
clinical cases in Southern Europe could be explained by the lack of movements of livestock coupled with the apparent lack of movements of wild hosts for ticks between the Western Mediterranean basin and the Balkans, leading to a lack of connectivity between eastern and western populations of the vector and virus [8]. However, it is of major epidemiological importance to point out that during the Eid-al-Adha festival, every year Tunisia imports up to 100,000 sheep from several countries including Romania where $27.8 \%$ had IgG antibodies specific to CCHFv [3]. During these festivals, the vast majority of Tunisians, as most Muslims, sacrifice sheep by themselves with guidelines focusing only on echinococcosis but not on CCHF prevention. In addition, the dates of the Islamic Calendar for Eid-al-Adha are drifting 10 days each year according to the Gregorian Calendar. In the next 10-15 years, Eid-al-Adha will occur in summer-autumn when CCHFv is more prevalent. Therefore, movement of livestock and wild hosts for ticks (mainly migratory birds) between North Africa and the Balkans, coupled with slaughtering activities during the Eid-al-Adha festival, particularly during summer-autumn, may lead to an increased risk of CCHFv in Tunisia [16]. Thus, preparedness for such a risk is of high importance [18].

In conclusion, our results provide strong evidence of circulation of $\mathrm{CCHFv}$ in Tunisia for the first time. Thus, further studies are recommended to be carried out on livestock, high risk groups of humans, birds, and ticks for a better understanding of the dynamic transmission of CCHFv in Tunisia and surrounding countries in North Africa.

\section{Conflict of interest}

The authors declare no conflict of interest in relation with this paper.

Acknowledgements. The authors would like to thank Nidal Abu Sammour and David Elliott, the two project managers from CRDF and UKBEP, respectively, for enabling this collaboration and providing funding. The views expressed are those of the authors and not necessarily those of the funding bodies or the employing institutions. The authors also thank Dr. Marie Petretto (Marwell Wildlife) for helping with tick collection.

$\mathrm{AL}, \mathrm{SD}$, and EZ designed the study. AL, MC, HT, MBJ, TG, and AL collected data. FW, SD, AB, TG, AV, EZ, RH, and AL analyzed data. EZ wrote the manuscript.

This work was supported by a grant from the US Civilian Research and Development Foundation (CRDF) and the UK Biological Engagement Programme (UKBEP).

\section{References}

1. Atkinson B, Chamberlin J, Logue CH, Cook N, Bruce C, Dowall SD, Hewson R. 2012. Development of a real time RTPCR assay for the detection of Crimean-Congo hemorrhagic fever virus. Vector-Borne and Zoonotic Diseases, 12, 786-793.

2. Bodur H, Akinci E, Ascioglu S, Öngürü P, Uyar Y. 2012. Subclinical infections with Crimean-Congo hemorrhagic fever virus, Turkey. Emerging Infectious Diseases, 18, 640-642.

3. Ceianu CS, Panculescu-Gatej RI, Coudrier D, Bouloy M. 2012. First serological evidence for the circulation of Crimean-Congo hemorrhagic fever virus in Romania. Vector-Borne and Zoonotic Diseases, 9, 718-721.

4. Chinikar S, Ghiasi SM, Naddaf S, Piazak N, Moradi M, Razavi MR, Afzali N, Haeri A, Mostafavizadeh K, Ataei B, KhalifardBrojeni M, Husseini SM, Bouloy M. 2013. Serological evaluation of Crimean-Congo hemorrhagic fever in humans with high-risk professions living in enzootic regions of Isfahan province of Iran and genetic analysis in circulating strains. Vector-Borne and Zoonotic Diseases, 12, 733-738.

5. Christova I, Gladnishka T, Taseva E, Kalvatchev N, Tsergouli K, Papa A. 2013. Sero-prevalence of Crimean-Congo hemorrhagic fever virus, Bulgaria. Emerging Infectious Diseases, 19, $177-1779$.

6. Ergonul O. 2006. Crimean-Congo hemorrhagic fever. Lancet Infectious Diseases, 6, 203-214.

7. Estrada-Pena A, Palomar AM, Santibanez P, Sanchez N, Habela MA, Portillo A, Romero L, Oteo JA. 2012. Crimean-Congo hemorrhagic fever virus in ticks, Southwestern Europe, 2010. Emerging Infectious Diseases, 18, 179-180.

8. Estrada-Pena A, Jameson L, Medlock J, Vatansever Z, Tishkova F. 2012. Unraveling the ecological complexities of tick-associated Crimean-Congo hemorrhagic fever virus transmission: a gap analysis for the Western Palearctic. Vector-Borne and Zoonotic Diseases, 12, 743-752.

9. Fajs L, Humolli I, Saksida A, Knap N, Jelovsek M, Korva M, Dedushaj I, Avsic-Zupanc T. 2012. Prevalence of CrimeanCongo hemorrhagic fever virus in healthy population, livestock and ticks in Kosovo. Plos One, 9, e110982.

10. Gergova I, Kamarinchev B. 2013. Comparison of the prevalence of Crimean-Congo hemorrhagic fever virus in endemic and non-endemic Bulgarian locations. Journal of Vector Borne Diseases, 50, 265-270.

11. Gharbi M, Hayouni ME, Sassi L, Dridi W, Darghouth MA. 2013. Hyalomma scupense (Acari: Ixodidae) in northeast Tunisia: seasonal population dynamics of nymphs and adults on field cattle. Parasite, 20, 12.

12. Hoogstraal H. 1979. The epidemiology of tick-borne CrimeanCongo hemorrhagic fever in Asia, Europe, and Africa. Journal of Medical Entomology, 15, 307-417.

13. Kautman M, Tiar G, Papa A, Široký P. 2016. AP92-like CrimeanCongo hemorrhagic fever virus in Hyalomma aegyptium ticks, Algeria. Emerging Infectious Diseases, 22, 354-356.

14. Knust B, Medetov ZB, Kyraubayev KB, Bumburidi Y, Erickson BR, MacNeil A, Nichol ST, Bayserkin BS, Ospanov KS. 2012. Crimean-Congo hemorrhagic fever, Kazakhstan, 2009-2010. Emerging Infectious Diseases, 18, 643-645.

15. Leblebicioglu H, Eroglu C, Erciyas-Yavus K, Hokelek M, Acici M, Yilmaz H. 2014. Role of migratory birds in spreading Crimean-Congo hemorrhagic fever, Turkey. Emerging Infectious Diseases, 8, 1331-1334.

16. Leblebicioglu H, Sunbul M, Memish ZA, Al-Tawfiq JA, Bodur H, Ozkul A, Gucukoglu A, Chinikar S, Hasan A. 2015. Consensus report; Preventive measures for Crimean-Congo hemorrhagic fever during Eid-al-Adha festival. International Journal of Infectious Diseases, 38, 9-15.

17. Lindeborg M, Barboutis C, Ehrenborg C, Fransson T, Jaenson TGT, Lindgren P-E, Lundkvist A, Nyström F, Salaneck E, Waldenström J, Olsen B. 2012. Migratory birds, ticks, and Crimean-Congo hemorrhagic fever, virus. Emerging Infectious Diseases, 18, 2095-2096.

18. Maltezou HC, Andonova L, Andraghetti R, Bouloy M, Ergonul O, Jongejan F, Kalvatchev N, Nichol S, Niedrig M, Platonov A, 
Thomson G, Leitmeyer K, Zeller H. 2010. Crimean-Congo hemorrhagic fever in Europe: current situation calls for preparedness. Euro Surveillance, 15(10), 19504.

19. Mardani M, Keshtkar-Jahromi M, Ataie B, Adibi P. 2009. Crimean-Congo hemorrhagic fever virus as a nosocomial pathogen in Iran. American Journal of Tropical Medicine and Hygiene, 81, 675-678.

20. M'ghirbi Y, Yaïch H, Ghorbel A, Bouattour A. 2012. Anaplasma phagocytophilum in horses and ticks in Tunisia. Parasites \& Vectors, 5, 180.

21. Mourya DT, Yadav PD, Shete AM, Gurav JK, Raut CG, Jadi RS, Pawar SD, Nichol ST, Mishra AC. 2012. Detection, isolation and confirmation of Crimean-Congo hemorrhagic fever in human, ticks, and animals in Ahmadabad, India, 2010-2011. Plos Neglected Tropical Diseases, 6, e1653.

22. Nabeth P, Cheick DO, Lo B, Faye O, Vall IOM, Niang M, Wague B, Dip D, Diallo M, Diallo B, Diop OM, Simon F. 2004. Crimean-Congo hemorrhagic fever, Mauritania. Emerging Infectious Diseases, 10, 2143-2149.

23. Onishchenko GG, Tumanova IIu, Vyshemirskii OI, Khun J, Seregin SV, Tiunnikov GI, Petrova ID, Tishkova FK, Ospanov KS, Kazakov SV, Karimov SK, Esmagambetova AS, Netesov SV, Petrov VS. 2005. ELISA and RT-PCR-based research of viruses in the ticks collected in the foci of Crimean-Congo fever in Kazakhstan and Tajikistan in 2001-2002. Voprosy Virusologii, 50, 23-26 (in Russian).

24. Palomar AM, Portillo A, Santibanez P, Mazuelas D, Arizaga J, Crespo A, Gutierrez O, Cuadrado JF, Oteo JA. 2013. CrimeanCongo hemorrhagic fever virus in ticks from migratory birds, Morocco. Emerging Infectious Diseases, 19, 260-263.
25. Rodriguez LL, Maupin GO, Ksiazek TG, Rollin PE, Khan AS, Scharz TF, Lofts RS, Smith JF, Noor AM, Peters CJ, Nichol ST. 1997. Molecular investigation of a multisource outbreak of Crimean-Congo hemorrhagic fever in the United Arab Emirates. American Journal of Tropical Medicine and Hygiene, 57, 512-528.

26. Sherifi K, Cadar D, Muji S, Robaj A, Ahmeti S, Jakupi X, Emmerich P, Krüger A. 2014. Crimean-Congo hemorrhagic fever virus clades V and VI (Europe 1 and 2) in ticks in Kosovo, 2012. Plos One, 9, e3168.

27. Sidira P, Maltezou HC, Haidich AB, Papa A. 2012. Seroepidemiological study of Crimean-Congo hemorrhagic fever in Greece, 2009-2010. Clinical Microbiology and Infection, 18, e16-e19.

28. Whitehouse CA. 2004. Crimean-Congo hemorrhagic fever. Antiviral Research, 64, 145-160.

29. Wilson ML, Gonzalez JP, LeGuenno B, Cornet JP, Guillar M, Calvo MA, Digoutte JP, Camicas JL. 1999. Epidemiology of Crieman-Congo hemorrhagic fever in Senegal: temporal and spatial patterns. Archives of Virology (Suppl 1), 323-340.

30. Yaser SA, Sadegh C, Zakkey T, Hassan V, Maryam M, Ali OM, Mojtaba GS. 2011. Crimean-Congo hemorrhagic fever: a molecular survey on hard ticks (Ixodidae) in Yazd province, Iran. Asian Pacific Journal of Tropical Medicine, 4, 61-63.

31. Yilmaz GR, Buzgan T, Irmak H, Safran A, Uzum R, Cevik MA, Torunoglu MZ. 2009. The epidemiology of Crimean-Congo hemorrhagic fever in Turkey, 2002-2007. International Journal of Infectious Diseases, 13, 380-386.

Cite this article as: Wasfi F, Dowall S, Ghabbari T, Bosworth A, Chakroun M, Varghese A, Tiouiri H, Ben Jemaa M, Znazen A, Hewson R, Zhioua E \& Letaief A: Sero-epidemiological survey of Crimean-Congo hemorrhagic fever virus in Tunisia. Parasite, $2016,23,10$.

\section{O PARASTE}

An international open-access, peer-reviewed, online journal publishing high quality papers on all aspects of human and animal parasitology

Reviews, articles and short notes may be submitted. Fields include, but are not limited to: general, medical and veterinary parasitology; morphology, including ultrastructure; parasite systematics, including entomology, acarology, helminthology and protistology, and molecular analyses; molecular biology and biochemistry; immunology of parasitic diseases; host-parasite relationships; ecology and life history of parasites; epidemiology; therapeutics; new diagnostic tools.

All papers in Parasite are published in English. Manuscripts should have a broad interest and must not have been published or submitted elsewhere. No limit is imposed on the length of manuscripts.

Parasite (open-access) continues Parasite (print and online editions, 1994-2012) and Annales de Parasitologie Humaine et Comparée (1923-1993) and is the official journal of the Société Française de Parasitologie. 